\title{
HABITAT USE BY THE GREAT INDIAN BUSTARD ARDEOTIS NIGRICEPS (GRUIFORMES: OTIDIDAE) IN BREEDING AND NON-BREEDING SEASONS IN KACHCHH, GUJARAT, INDIA
}

\section{Sandeep B. Munjpara ${ }^{1}$, C.N. Pandey ${ }^{2} \&$ B. Jethva ${ }^{3}$}

${ }^{1}$ Junior Research Fellow, ${ }^{3}$ Scientist, GEER Foundation, Indroda Nature Park, P.O. Sector-7, Gandhinagar, Gujarat 382007, India

${ }^{2}$ Additional Principal Chief Conservator of Forests, Sector-10, Gandhinagar, Gujarat 382007, India

${ }^{3}$ Presently address: Green Support Services, C-101, Sarthak Apartment, Kh-0, Gandhinagar, Gujarat 382007, India

${ }^{1}$ sandeepmunjpara@gmail.com (corresponding author), ${ }^{2}$ pandeycn08@rediffmail.com, ${ }^{3}$ bharatjethva2000@yahoo.co.in

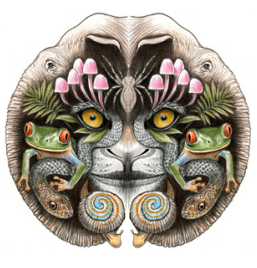

ISSN

Online 0974-7907

Print 0974-7893
Abstract: The Great Indian Bustard Ardeotis nigriceps, a threatened and endemic species of the Indian subcontinent, is declining in its natural habitats. The Great Indian Bustard is a bird of open land and was observed using the grasslands habitat (73\%), followed by areas covered with Prosopis (11\%). In the grasslands, the communities dominated with Cymbopogon martinii were utilized the highest, while those dominated by Aristida adenemsoidis were least utilized. As Cymbopogon martinii is non-palatable, we infer that it does not attract livestock and herdsmen resulting in minimum movement and trampling that favors the Great Indian Bustard.

Keywords: Cymbopogon martini, grassland, Great Indian Bustard, habitat preference, seasonality.

The Great Indian Bustard Ardeotis nigriceps is an endemic species of the Indian subcontinent (Ali \& Ripley 1998; Rahmani 2006) and recently upgraded as Critically Endangered (BirdLife International 2011). The Great Indian Bustard (GIB) is distributed in six states of India, namely, Gujarat, Rajasthan, Maharashtra, Andhra Pradesh, Madhya Pradesh and Karnataka (Rahmani 2006). In Gujarat, it was earlier found in most of the grasslands of Saurashtra and Kachchh regions (Dharmakumarsinhji 1957, 1962a,b, 1978). Presently, the only surviving population is recorded from a small pocket of Kachchh
District (Pandey et al. 2009; Munjpara et al. 2011).

In order to develop effective conservation strategies for the long term survival of GIB, it is important to know its detailed habitat requirements. Determination of various habitats and their utility by the species was carried out to understand whether the grassland is sufficient enough for detailed management planning. The present study made a systematic effort to find out the availability of various habitat types and also habitat preference and utilization by the species. This data will be crucial for understanding the biological requirement of this species in its current distribution range and will be helpful in detailed planning of conservation and management strategies for long term survival of the species in Gujarat.

\section{Study area}

The habitat preference of GIB was studied in the Naliya grassland located in the southwestern taluka of Abdasa in Kachchh District (Fig. 1). Fewer amounts of precipitation and frequent drought condition in this area do not support the growth of big tree species,

DOI: http://dx.doi.org/10.11609/JoTT.02757.3654-60 | ZooBank: urn:Isid:zoobank.org:pub:7482F4E8-11D8-4A69-ABDA-3044D59EB007

Editor: C. Srinivasulu, Osmania University, Hyderabad, India.

Date of publication: 26 February 2013 (online \& print)

Manuscript details: Ms \# 02757 | Received 08 April 2011 | Final received 23 January 2013 | Finally accepted 07 February 2013

Citation: Munjpara, S.B., C.N. Pandey \& B. Jethva (2012). Habitat use by the Great Indian Bustard Ardeotis nigriceps (Gruiformes: Otididae) in breeding and non-breeding seasons in Kachchh, Gujarat, India. Journal of Threatened Taxa 5(2): 3654-3660; doi:10.11609/JoTT.02757.3654-60.

Copyright: (C) Munjpara et al. 2013. Creative Commons Attribution 3.0 Unported License. JoTT allows unrestricted use of this article in any medium, reproduction and distribution by providing adequate credit to the authors and the source of publication.

Funding: None.

Competing Interest: None.

Acknowledgements: We are thankful to the Ministry of Environment and Forests, Government of India for financially supporting the present study. We sincerely acknowledge the valuable support received from Gujarat Forest Department. We extend our deep gratitude towards the forest officers of Kachchh Circle who constantly helped us out during various field visits. We are grateful to the staff members of GEER Foundation for helping and supporting our various activities for the project. 


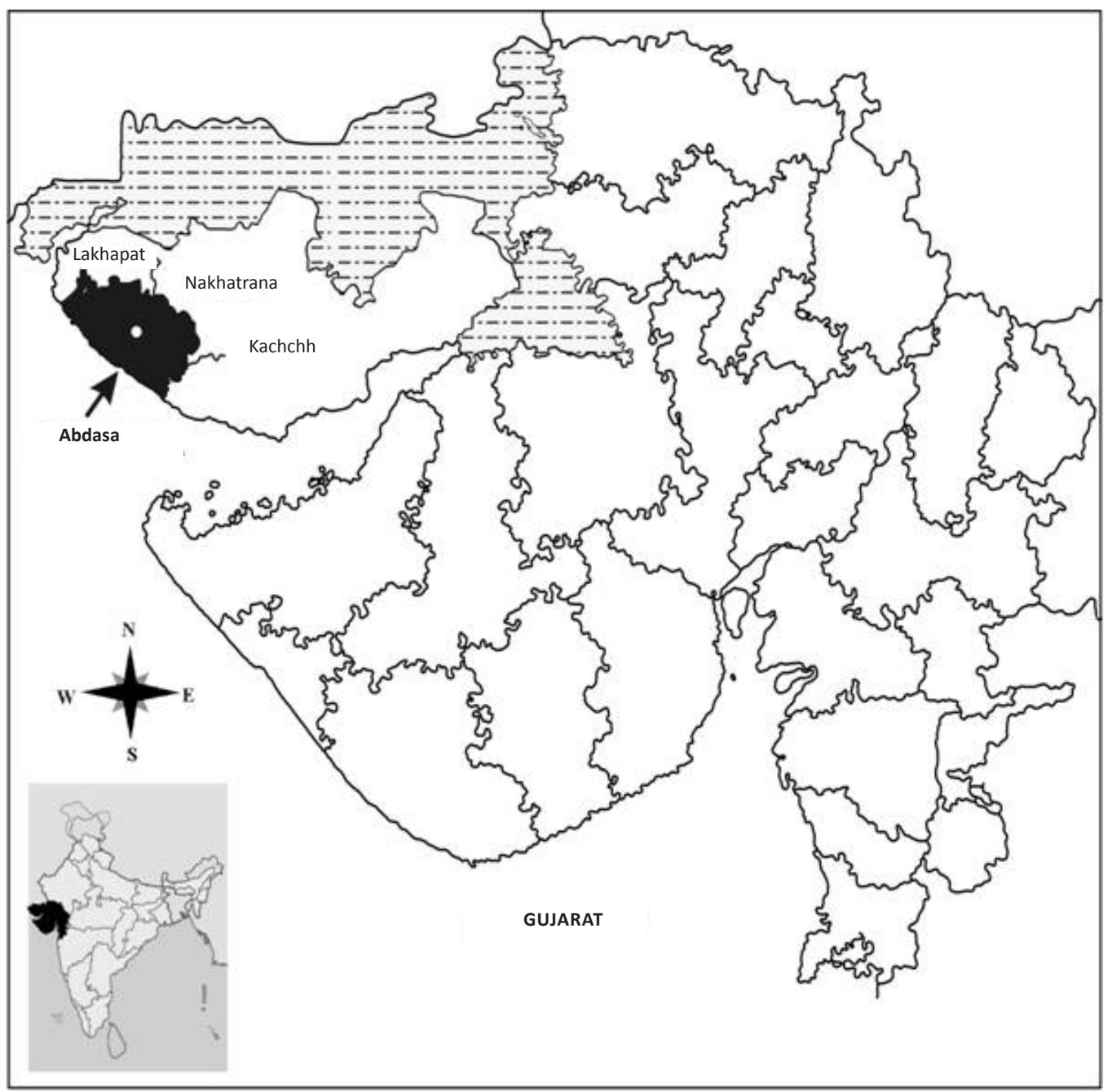

Figure 1. Study area

and moisture from the air supports the growth of the grass. Ecologically, this area is of the type of 5A/DS 4-Dry grassland with few scattered patches of 5A/DS 2-Dry Savannah forest (Champion \& Seth 1968). Both continuous and discontinuous patches of grassland were observed in the study area; some areas covered with only grasses and forbs, and other areas covered with grass, forbs as well as with scattered bushes of Acacia spp., Prosopis juliflora, Prosopis cineraria, Zizyphus spp., Salvadora spp., and Capparis spp. The area supports many threatened wildlife. It holds almost $33 \%$ of the total bird species of Gujarat State (Munjpara \& Gadhvi 2012).

\section{Methods}

The study of the habitat preference of GIB was carried out by comparing available habitats and habitats used by the species. Field data collection was carried out from July 2006 to October 2007. The methods followed are as given below:

Step 1: Delineation of intensive area/total distribution of GIB: In order to determine the total availability of various habitats, the intensive study area or the total area of annual distribution range was considered. Therefore, a $100 \%$ minimum convex polygon (MCP) was generated by plotting all the locations where GIB was observed during the entire study period. An area of $996.76 \mathrm{~km}^{2}$ falling within $100 \%$ MCP was further used for quantifying the habitat availability.

Step 2: Quantification of available habitats of GIB: A satellite image (IRS-P6- LISS-III, of 10 December 2006 of path 89 and row 55) of the intensive study area was procured for habitat analysis. The satellite image of the study area was classified into major habitat types using unsupervised classification in ERDAS software. The delineated intensive study area (100\% MCP) was superimposed on the classified satellite image of the study region and areas of various habitat types were 
calculated using GIS domain. A total of nine different habitat categories were identified as: (i) grassland, (ii) open scrubland, (iii) agriculture land, (iv) prosopis, (v) open land, (vi) water body, (vii) rocky, (viii) mudflat, and (ix) salt affected and sandy areas.

Preliminary maps were prepared and taken back to the field for further verification and ground-truthing. After ground-truthing and corrections, final maps on a 1:50,000 scale were prepared. The areas under various habitat categories within the total distribution range were calculated and the proportional availability of various habitats was calculated.

Step3: Quantification of used habitats of GIB: A total of 22 field visits (of which nine visits were during the breeding season) were made to the study area covering almost all the months and all the three major seasons of the year. During these field visits, sighting point locality coordinates were recorded using GPS. These observed locations were plotted on the above mentioned classified satellite image of the total distribution range of the species. The number of bird observation locations falling in each category of habitats was calculated and proportional uses of various habitats were quantified. The grassland habitats were further analyzed at community levels. The grassland area was further divided on the basis of grass species compositions. Various area polygons were marked based on the dominant grass species. Qualitative classification of dominant species in terms of percentage (more than $60 \%$ ) cover by a particular species was considered to make various subcategories within the broad category of grassland. The sightings of the species within various grass communities were quantified for further statistical analysis.

Step 4: Statistical analysis: Chi-square test was conducted to understand the habitat use and preference by the bird for this study (Jethva \& Jhala 2003). The observed proportional uses of various habitat categories were tested against the proportional availability of each habitat categories. The grassland in the study area could be further differentiated into five grass communities based on the dominant species. The communities of various grass species were classified based on the species that dominated more than $60 \%$ in a particular grassland patch. The proportion of all five different types of grass communities present in the distribution range were considered as available to the species. If the bustards showed no preference to any particular grass community then they were expected to use these different grass communities randomly or use in proportion to their availability (null hypothesis).

\section{Results and Discussion}

Available habitats to Great Indian Bustards in the study area: A total of nine broad land cover classes/ habitat categories could be identified using remote sensing techniques within the study area in Gujarat. The description on the ecological condition of the various habitats, their area and proportions are given below.

(1) Grassland: Nearly 28,257 ha area is covered by flat grasslands. These coastal grasslands are locally known as "Doan" cover a total of $28.4 \%$ of the total extent of the study area. These grasslands are composed of major grass species belonging to the genera Cymbopogon, Chrysopogon, Dicanthium and Aristida. The average grass height varies in different zones based on the species combination and the grazing pressures, and was found to be between 0.38 and $1 \mathrm{~m}$ in the region between two consecutive good rain years. Depending on the location, these grassland areas were divided into four zones-Kanothia, Bhanada, Naliya, and Jakhau. The grassland habitats are patchy as they are fragmented due to the presence of various villages, habitations, village roads, highways, agriculture fields and defence establishments.

(2) Open land: The barren areas devoid of any vegetation were considered as open areas. The open land constitutes a total of $27,783 \mathrm{ha}(27.9 \%)$.

(3) Open scrubland: A total of $15,685 \mathrm{ha}(15.7 \%)$ was composed of open scrubland. This category includes sparse vegetation such as herbs and small grasses that are interspersed with shrubs such as Zizyphus sp., Acacia sp., and shrubs such as Prosopis juliflora, P. cineraria.

(4) Agriculture land: A total 11,685 ha $(11.7 \%)$ was found to comprise agriculture land. Agricultural land is well interspersed with grasslands. The agriculture practiced in the region is dry and rain fed and only one crop is cultivated during the year. The major crops in the region are ground nut, cotton, millet, sorghum and cumin. The majority of the fields remain fallow post harvesting throughout the year.

(5) Rocky area: A total of 330 ha $(0.3 \%)$ is comprised of rocky area which include small hillocks and undulating areas.

(6) Salt affected/sandy area: A total of 4,766ha (4.8\%) along the saline water creeks of Gulf of Kachchh and some wasteland area with accumulated white salt on the surface.

(7) Water body: A total of only $909 \mathrm{ha}(0.9 \%)$ include freshwater and saline water sources. The seasonal shallow watershed, check-dams, ponds and village ponds are important water sources for wildlife in the region. However, the water category also includes the 
saline water.

(8) Prosopis cover: The dense to sparse scrub patches of Prosopis juliflora makes a total of $10,089 \mathrm{ha}(10.1 \%)$ of the total distribution range of GIB in the region.

(9) Mudflat: A total of $134 \mathrm{ha}(0.1 \%)$ is located mainly on the coastal area of the Arabian Sea and on the edges of various creeks and water bodies such as ponds, checkdams, dams and reservoirs.

Habitat utilization: The proportional use of various available habitats by GIB was quantified during the study period based on the proportional frequency of sightings of the bird in different available habitats within their distribution range (Fig. 2). A total of 118 observations, constituting $73.3 \%$, out of 161 sightings were made in grasslands indicating that the grassland habitat is more frequently used. Other habitats were used less frequently (Prosopis juliflora shrub cover $11.2 \%$, open scrubland $8.1 \%$, open land $6.8 \%$, agriculture $0.6 \%$ ). However, the rest of the habitats such as salt affected area, rocky area, water body and mudflats were found to be avoided by GIB.

Habitat preference: Our analysis of habitat use suggests that there was a significant variation (Chisquare $=107.2, \mathrm{df}=8, \mathrm{p}<0.001$ ) between the proportion expected and the observed uses of various habitat types. Our observation suggests that the habitats such as grassland and Prosopis cover were proportionally used more than their availability (Fig. 2; Images 1-4).
Seasonal utilization of habitats by the GIB: The seasonal utilization of various habitat types did not show major differences in their utilization pattern in all the seasons (Fig. 3). Utilization of Prosopis cover was higher in monsoon than in summer and it was utilized almost in proportion to its availability in winter. The Prosopis provides shelter to the bustards in summer and winter against the sun and chilly winds, respectively. However, the edges of Prosopis cover were observed to be used by female bustards to hide their young ones during the breeding season, in the monsoon.

The preference of grassland communities by the GIB in core areas: Though the bustards were distributed in a total of $996.4 \mathrm{~km}^{2}$ area, the grassland habitat, their most preferred habitat, totals $282.6 \mathrm{~km}^{2}$ covered with grassland patches of various sizes. Of these grassland patches, an area of $97.0 \mathrm{~km}^{2}$ is more or less continuous where maximum sightings were recorded and hence categorized as the core zone during the study period. These areas are mainly the grasslands of Kanothia, Kalatalav, Bhachunda, Banada, Tera, Naliya, Vinghaber, Parjau, Lala, Jakhau and Budia villages. This grassland area could be further divided into various grass communities based on the occurrence of the dominant species of grasses. Of these important grassland patches, an area of 3,663ha (37.7\%) is dominated by Cymbopogon martinii. The other patches of grasslands were dominated with Dicathium annulatum (2,700ha) followed by Aristida

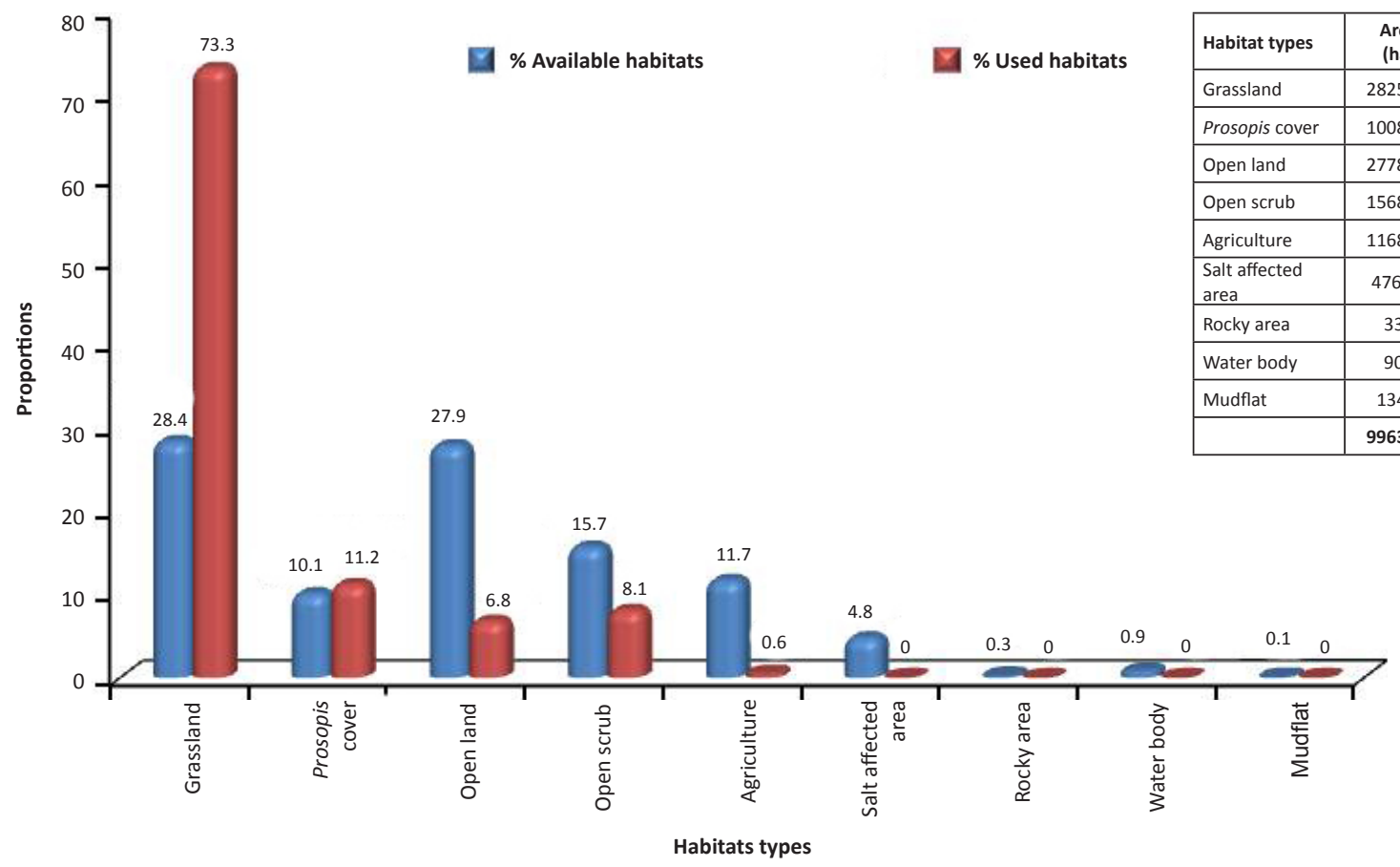

Figure 2. Proportional availability and use of various habitat types in the distribution range of GIB in Gujarat 


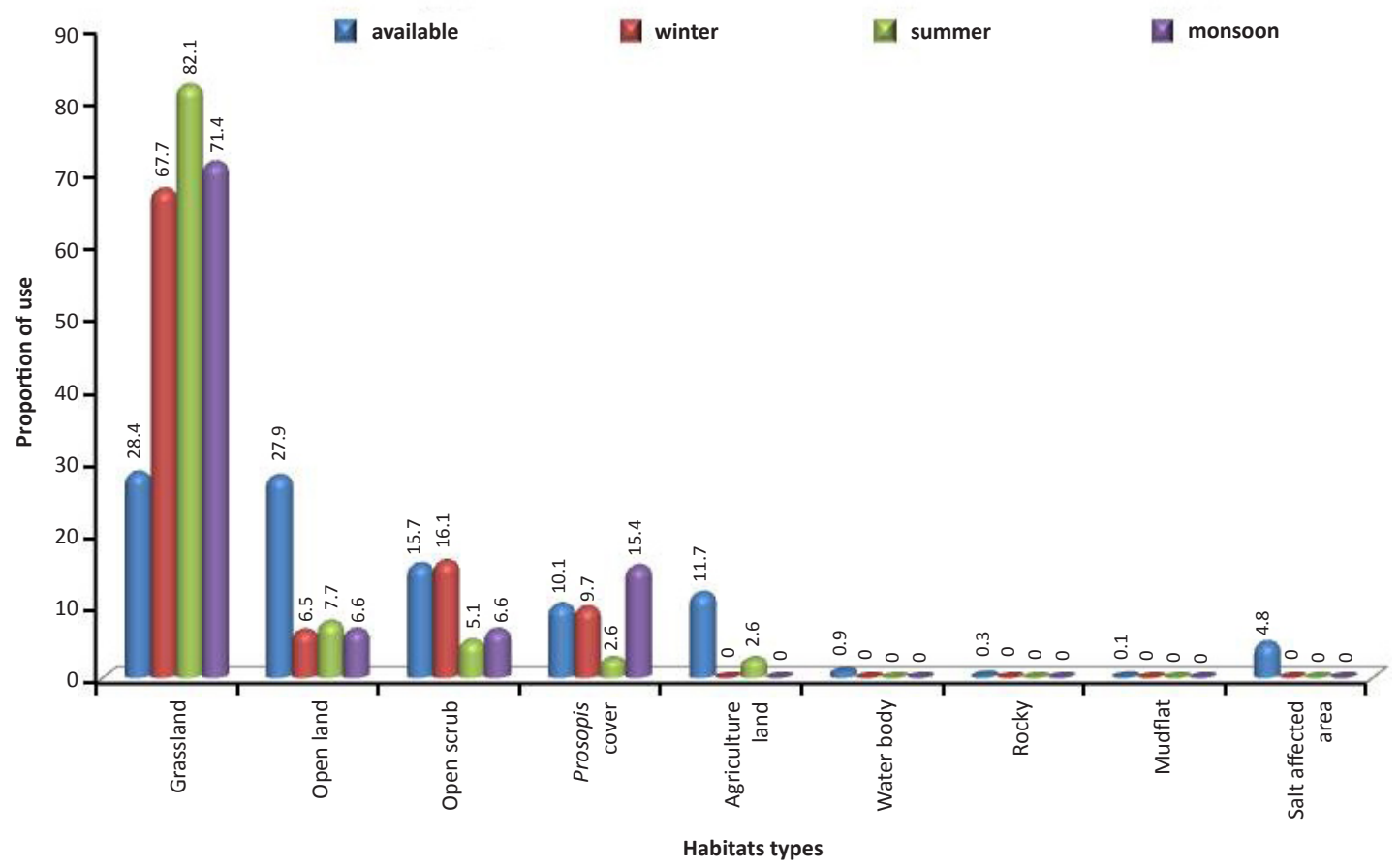

Figure 3. Proportional seasonal use of various habitats by GIB observed in its distribution range in Gujarat

spp. (1,397ha) and Glossocerdia boswellia (1,892ha). In some patches mixed species, forbs and shrubs were also observed (Fig. 4). A significant variation (Chisquare $=69.47, \mathrm{df}=4, \mathrm{p}<0.005$ ) between the proportion expected and observed uses of various grass community types was obtained. Our observation suggests that the Cymbopogon-dominated and mixed species grasslands are used more than their proportional availabilities in the total grassland area (Fig. 4). However, Dicanthium sp. and Aristida sp. areas were used less by the GIB. The reason for the preference of Cymbopogon-dominated grassland areas is likely due to fewer disturbances caused to birds in this grass community. Since Cymbopogon is a non-palatable grass species these areas do not attract livestock and herdsmen which result in minimum movement and trampling in the area (Rajput 2008).

Breeding and nesting habitats of the GIB: Observations were also made on the breeding ecology of the GIB. Habitats used during courtship display and nesting were studied.

Display of Male (Lekking): Courtship display or 'lekking' was observed from April to October. Intensive and aggressive display was observed between June to August. Of the total seven courtship displays observed, three were found to be in Cymbopogon martinii dominated area and three were in Glossocerdia boswellia dominated area and one in saline grassland area. The grass height was observed to be 6-10 inch at all the display sites. Of these displays six were found in grassland patches of Naliya and one was found in Jakhau.

Nesting habitats: Nesting was recorded from April to September months during the study period. A total of nine nests were observed in the core area including grassland patches of Kanothia, Naliya and Jakhau (sanctuary area) dominated by Cymbopogon martinii.

There are a number of favorable biophysical conditions that hold the GIB population in their present distribution range in Kachchh. The unique combination of climatic condition, topography, location, geology and habitat types make this area a distinct ecosystem with a unique assemblage of floral and faunal species. The scanty and erratic rainfall, high wind speed, and extremes of temperatures result in high evapotranspiration rates which causes rapid drying of water sources in the region. Such conditions are not favorable for growth of trees and other luxuriant vegetation excluding the grasses and scrub in the region. The climatic conditions along with geology, topography and sparse human population favor the existence of a grassland that supports the population of the GIB in this area. The distribution range of the GIB is a mosaic of various habitat types such as grasslands, scrubland, agriculture fields, open land and human settlements. The area is relatively flat with few low hillocks and deep ridges created by the seasonal drainages. Due to the flatness of the plain, 


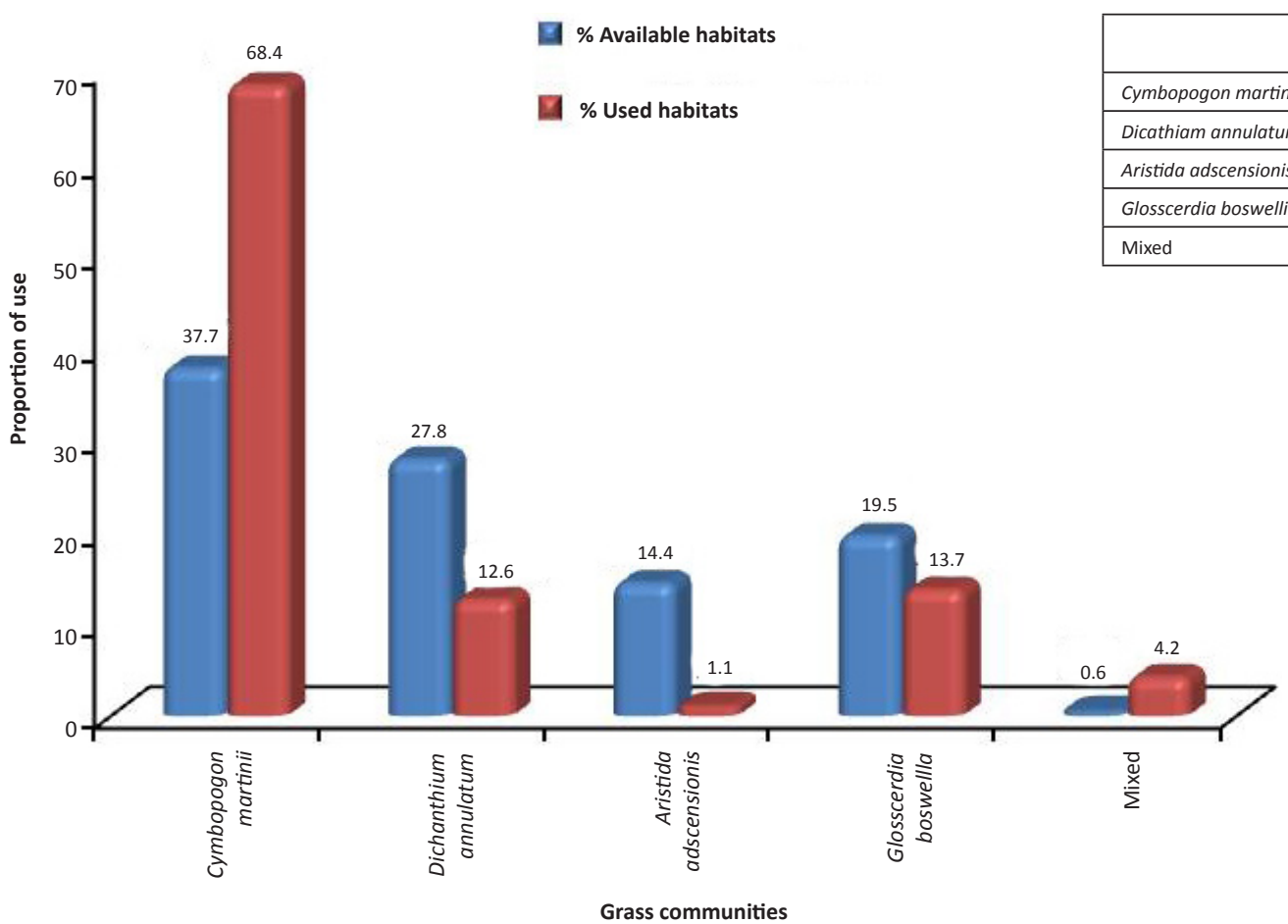

Figure 4. Proportional availability and use of various grass communities in the distribution range of GIB in Gujarat

presence of sparse vegetation, short grasses and open land, the visibility is high in the grassland habitat which favors the survival of the heavy-bodied bustard. The invasion by Prosopis juliflora is prominent in some of the areas particularly on the periphery of grasslands. The majority of the grass species remains green (Image 3) during the rainy days and start becoming paler yellow as winter approaches (Image 1) and become completely dry during summer (Image 2). However, as the area is located on the coast of Arabian Sea, the sea breeze carrying moisture help the growth of summer shoots of Cymbopogon, which makes a considerable portion of the food items for the herbivore Spiny-tailed Lizard (Saara hardwiicki) in the region (Dutta \& Jhala 2007). This diurnal lizard is prey to the many carnivorous birds and mammals including the bustard. The Great Indian Bustard is an omnivore and feeds mainly on snakes, lizards, insects and plant seeds. This unique grasslandscrubland ecosystem harbors a number of important species and has a higher conservation significance deserving recognition and conservation efforts for the long term survival of a unique assemblage of wildlife species including the Critically Endangered Great Indian Bustard.

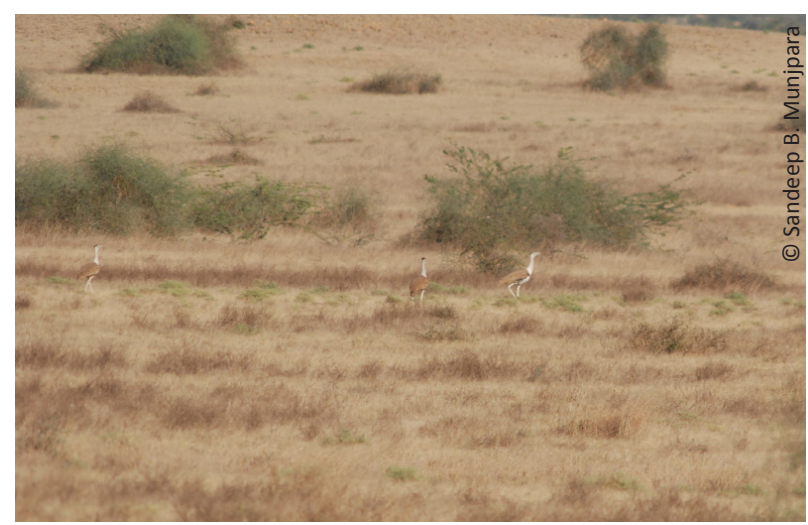

Image 1. Grassland interspersed with scrub

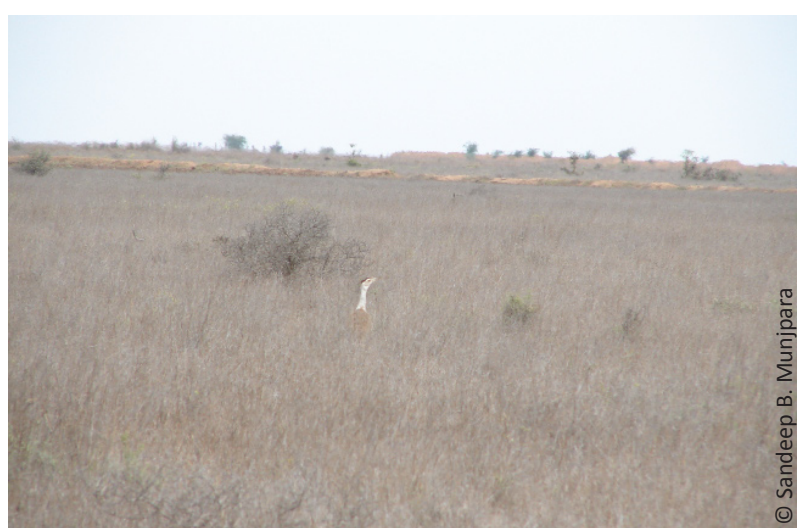

Image 2. Grassland: more preferred Cymbopogon martinii grass community 


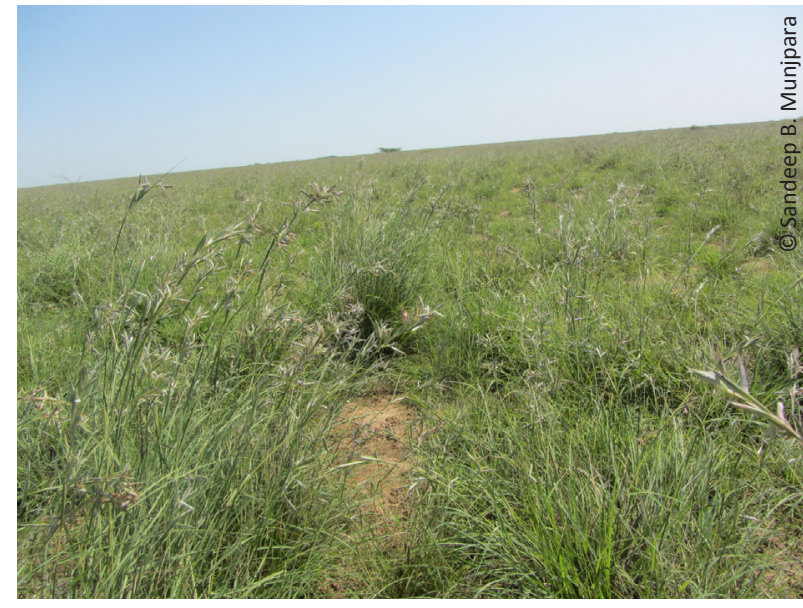

Image 3. Grassland, dominated with Cymbopogon martinii

\section{REFERENCES}

Ali, S. \& S.D. Ripley (1998). Handbook of the Birds of India and Pakistan. Oxford University Press, Delhi. Vol. 2, 347pp.

BirdLife International (2011). Threatened Birds of Asia. CD-ROM, The BirdLife International Red Data Book. Cambridge, UK.

Champion, H.G. \& S.K. Seth (1968). A Revised Survey of Forest Types of India. Government of India Publication, New Delhi, 404pp.
Dharmakumarsinhiji, K.S. (1957). Ecological Study of the Great Indian Bustard Ardeotis nigriceps (Vigor) (Aves: Otididae) in Kathiawar Peninsula, Western India. Journal of Zoological Society of India 9: 140-152.

Dharmakumarsinhji, K.S. (1962a). The Indian Bustard Choritis nigriceps (vigor) at the nest. Journal of the Bombay Natural History Society 59: 173-184.

Dharmakumarsinhji, K.S. (1962b). Display, posturing and behavior of Indian Bustard. Second All-India Congr. Zoology 1-11pp.

Dharmakumarsinhji, K.S. (1978). The changing wildlife of Kathiawar. Journal of the Bombay Natural Society 75: 632-650.

Dutta, S. \& Y. Jhala (2007). Ecological aspects of Indian spiny-tailed Lizard Uromastyx hardwickii in Kutch. Journal of the Bombay Natural Society 104(3): 255-265.

Jethva, B.D. \& Y.V. Jhala (2003). Feeding ecology and habitat need of Wolves Canis lupus pallipes in Bhal area of Gujarat. PhD Thesis submitted to FRI University, Uttarakhand, 330pp.

Munjpara, S.B., B. Jethva \& C.N. Pandey (2011). Distribution of the Indian Bustard Ardeotis nigriceps (Gruiformes: Otididae) in Gujarat State, India. Journal of Threatened Taxa 3(9): 2090-2094.

Munjpara, S.B. \& I.R. Gadhvi (2012). Avian diversity in the Naliya Grassland, Abdasa Taluka, Kachchh, India. Journal of Threatened Taxa 4(3): 2454-2463.

Pandey C.N., B. Jethva \& S. Munjpara (2009). Status, distribution and habitat survey of Great Indian Bustard (Ardeotis nigriceps) in Gujarat. Gujarat Ecological Education and Research Foundation, 167pp.

Rahmani, A. R. (2006). Need to start Project Bustards. Bombay Natural History, Mumbai, 20pp.

Rajput, A.D. (2008). The Great Indian Bustard (Ardeotis nigriceps) on the verge of Extinction. Current Science 95(9): 1108-1109. 